\title{
Covid-19 Lockdown: An Opportunity to Explore New Frontiers For Online-Training
}

\author{
Dr DK Pandey*
}

\begin{abstract}
The nationwide closures of educational institutions due to the COVID-19 pandemic have made impact over $87 \%$ of the world's student population, as claimed by UNSECO. This pandemic has impacted the prevailing conventional education systems in ways that have no precedence in recent times. In response to this environment, educational Institutions have resorted to distance learning solutions. While, online-teaching and virtual simulation are proven tools for skill development in young personalities, 'Virtual Simulation aided training' do have challenges due to inherent tangible and intangible limitations and characteristics. Nevertheless, online-training is a vital and exclusive instrument to boost the educational productivity during pandemic like situations. Sudden onset of the pandemic has made the transition into online education bit tedious. In order to address the end objective of online education, it is inevitable that the eLearning objective has to be a focused activity. To achieve the eLearning objectives the concerted effort has to be made to streamline and standardize methodologies. It is to be ensured that the value-based training architecture shall complement cognitive learning also. This paper looks at various concepts and methodologies with the intent of providing a framework for standardization of online education.
\end{abstract}

Keywords: Online-Training, Virtual simulation, eLearning, Training, Education during lockdowns, educational productivity, skill development 


\section{Covid-19 Lockdown: An Opportunity to Explore New Frontiers For Online-Training}

\section{Introduction}

Most of the educational institutions have been temporarily closed in an attempt to contain the spread of the COVID-19 pandemic. These worldwide closures of educational institutions are impacting more than of $87 \%$ of the world's student population. In addition, several countries have implemented localized closures impacting millions of additional learners. "Never before have we witnessed educational disruption on such a scale," said UNESCO Director-General Audrey Azoulay (UNESCO, 2020).

Nevertheless, the rapid spread of COVID-19 has pushed Educational Institutions to respond promptly to the crisis. It is not feasible to have conventional mode of training as face-to-face sessions in this environment due to obvious health concerns. Thus conducting 'Training' in lockdown scenario due COVID-19 pandemic is a challenge. In such scenario only possibility of training is through 'Online Classes'. It's a new environment as it is a technology-centric activity. In addition to devices (gadget) to connect, adequate level of awareness to exploit the technology are essential ingredients for such online-training.

Notwithstanding the challenges involved, online teaching by faculties / teachers wherever it was possible was allowed as an alternative. This alternative, with the support of technology, has been one of the most effective ways to respond to the crisis for addressing the needs of student community.

\section{Abrupt Change in Educational Environment}

Various educational Institutions provide essential learning across the population without any discrimination. Lockdown due COVID-19 pandemic immobilised all the running-systems. The Children and youth were deprived of opportunities for growth and development due to unexpected closure for prolonged period. In India 330 million students have been away from Schools since 16 Mar 2020. 
According to UNESCO-reports, as given in the chart below (Fig 1), most of the Governments around the world have temporarily closed educational institutions in an attempt to contain the spread of the COVID-19 pandemic.

Fig 1: COVID-19's Staggering Impact on Global Education

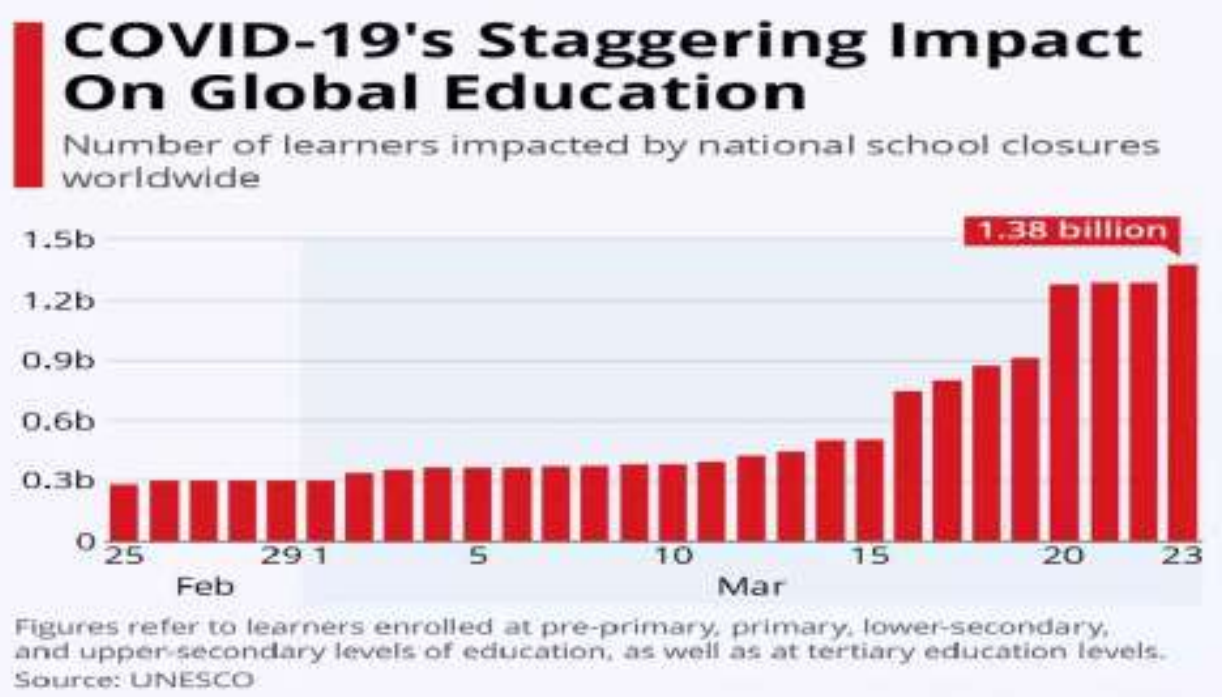

The UNESCO (UNESCO, n.d.) data gives the insight of the Global Education status as shown in Figure above. The salient features are:
(a) Affected learners
: 1.38 Billion
(b) Total enrolled learners
$: 68.5 \%$
(c) Country-wide closures
$: 153$

In such a time, the only recourse that universities and institutions across the globe can resort to is online-teaching.

For example, Cathay Li and Farah Lalani reported that the Chinese government instructed a quarter of a billion full-time students to resume their studies through online platforms. This resulted in the largest "online movement" in the history of education with approximately 730,000 , or $81 \%$ of K12 students, attending classes via the Tencent K-12 Online School in Wuhan (Li \& Lalani, 2020). While many countries including India resorted to online mode of education, with the bus of onlineteaching starting to run on the road of the internet, data usage has dashed up 25-30 per cent since the lockdown began in India, as reported by Economic Times (PTI, 2020). A report by ET (PTI, 
2020) finds that the usage of fixed line internet has surged by 25-30 percent. Notwithstanding such high usage, in the context of education, recourse to technology for education is also linked to social welfare in many developing countries.

For example, one of the most pressing problems faced by low and middle-income countries is to prevent child malnutrition in vulnerable areas by providing nutritious meal for children in school along with free schooling. Currently, a large percentage of young children in the developing world get most of their daily food intake at school. The COVID crisis has left 368 million children without access to school meals due to school closures (UNESCO, 2020), thereby depriving them both of education and nutrition.

Even a rudimentary assessment of its impact indicates that the educational sector is faced with a problem that requires transition from existing strategy to a novel strategy. To paraphrase from McDaniel and Schlager (McDaniel \& Schlager, 1990), the primary benefit of discovery (of this challenge) is that it should facilitate transfer to tasks requiring a novel strategy. The challenge of Covid19 is not limited to finding alternatives in the form of online classrooms alone. It also warrants a look at the need for training teachers as well as children to create skill sets that are essential to meet the objective of education - imparting knowledge. Having been brought up in traditional training modules, many of the mid and senior teachers in educational institutions would themselves face challenges in adopting to online training methodology. Hence, cross training to upgrade their skills to leverage technology would be a pre-requisite. Studies in industries have found that sound cross-training methodologies are needed to obtain desired outcomes (Marks, Sabella, Burke, \& Zaccaro, 2002). The question that merits attention therefore is: Do we need to train the providers and consumers of education during Lockdown period?

\section{Training}

Mud, Sand, Clay have always been considered as dust or waste. When same mud is transformed into shapes and structures expressing beauty and graceful art, it captures the human attraction. A knife is made usable only by 'Sharpening'. Training is a process of polishing the skills of an individual. Therefore, 'Training' is the catalyst for honing competencies of the workforce. It is a most vital part of the response to Covid19 and must be given supreme priority. 
The COVID-19 crisis has brought to the forefront the need to focus on eLearning. Given the nature of the crisis, all countries need to offer support to the most vulnerable children from being further marginalized and ensure they remain engaged in learning. Equity and inclusion in learning needs to continue being a key objective in crisis management.

As UNESCO observed, calendared assessments, notably high-stakes examinations that determine admission or advancement to new education levels and institutions, are thrown into disarray when schools close (UNESCO, n.d.).

It is also further observed that for those who do have access to the right technology, there is evidence that learning online can be more effective in a number of ways. A research by 'SHIFT eLearning' shows that on average, students retain 25-60\% more material when learning online compared to only $8-10 \%$ in a classroom. E-learning requires $40-60 \%$ less time to learn than in a traditional classroom setting (Gutierrez, 2016).

Studies conducted by Branden Hall Group found that class room, in-person training is more costly while remaining less effective (Wentworth, 2016). The key factor of course is the leveraging of technology. Various important paybacks of online training are as appended below.

(a) Growth drivers, Students, continue to get nurtured for growth a country.

(b) Enhanced understanding on the subjects.

(c) Need not to have multiple sections of a class / course, as all students may be combinedly taught together.

(d) Limited educational resources are required. Online classes reduce demands of teachers.

(e) Bare minimum load on the management of the educational institution.

(f) Less discipline issues.

(g) Utilisation of E-books will save paper and trees.

\section{Forms of Training}

The effectiveness of any training program is determined not only by the successful acquisition of critical knowledge but also the ability to effectively transfer that knowledge to the performance environment (Ellis, Bell, Ployhart, Hollenbeck, \& Ilgen, 2005). Therefore, during pandemic like 
scenario, conduct of user friendly and appropriate online-training in an institution becomes necessary.

The training-plan may be structured based on nature and objectives of the online-training. It may be conducted in the form of Informal Interactions, Subjective Q\&A sessions, animation-based discussions on various subjects, short duration audio \& / or video clips etc. Any tried and proven mode may be selected based on experience with the target trainees.

\section{Essentials of Training}

For successful conduct online-training in any organisation a well-structured curriculum needs to be prepared. This plan needs to comprise the time-based activities, resources, adequate support, suitable venue and skilled supervisors. Other vital aspects meriting consideration are as below:

(a) It has to be objective-specific.

(b) Availability of essential resources at both the ends i.e. at the ends of Teacher \& students, is pre-requisite for any online training. Resources required are Connecting Devices - PC / Laptops / tablets with webcam, headset, internet connectivity with adequate internet upload \& download data speeds, relevant video conferencing application etc.

(c) Serviceable hardware Resources and its regular replenishment to avoid any hindrance in conduct of planned training activities.

(d) Capable / qualified training team.

\section{Limitations of Online Classes.}

Despite obvious advantages over in-class education, online education has challenges and limitations as observed in many studies. The UNESCO Institute for Statistics, which develops the indicators and methodologies needed to track progress towards international education goals, for example, has highlighted various limitations of the online-training, in its report (UNESCO, 2020).

- $\quad$ Interrupted learning: The disadvantages are disproportionate for under-privileged learners who tend to have fewer educational opportunities beyond school.

- $\quad$ Poor nutrition: Many children and youth rely on free or discounted meals provided at schools for food and healthy nutrition. When schools close, nutrition is compromised. 
- Confusion and stress for teachers: When schools close, unexpectedly and for unknown durations, mostly teachers are often unsure of their obligations and how to maintain connections with students to support learning.

- $\quad$ Parents unprepared for distance and home schooling: When schools close, parents are often asked to facilitate the learning of children at home and can struggle to perform this task. This is especially true for parents with limited education and resources.

- $\quad$ Gaps in childcare: In the absence of alternative options, working parents often leave children alone when schools close and this can lead to risky behaviours, including increased influence of peer pressure and substance abuse.

- $\quad$ High economic costs: Working parents are more likely to miss work when schools close in order to take care of their children. This results in wage loss and tend to negatively impact productivity.

- Increased pressure on schools and school systems that remain open: Localized school closures place burdens on schools as governments and parents alike redirect children to schools that remain open.

- $\quad$ Rise in dropout rates: It is a challenge to ensure children and youth return and stay in school when schools reopen after closures. This is especially true of protracted closures and when economic shocks place pressure on children to work and generate income for financially distressed families.

- $\quad$ Increased exposure to violence and exploitation: When schools shut down, early marriages increase, more children are recruited into militias, sexual exploitation of girls and young women rises, teenage pregnancies become more common, and child labour grows.

- $\quad$ Social isolation: Schools are hubs of social activity and human interaction. When schools close, many children and youth miss out of on social contact that is essential to learning and development.

\section{Other Implications}

Studies by Panotop which has been working with universities and companies in USA on employee and educational training find that there are seven primary reasons why training fails like Limited 
Time and Competing Priorities, Lack of Interest, Limited Budget and Training Resources, Information Overload, Lack of Planning and Poor Timing, Neglecting What Happens After Training, and Relying On Technology To Do The Work For You (Panotop, 2019). Taking such lessons forward, studies by scholars like Rama Devi and Shaik (Rama Devi \& Shaik, 2012) find that it is not just sufficient to conduct a training program. Organizations should evaluate whether training \& development programs are effective and producing desired results. Proper evaluation is the base to effective training. Training evaluation should be a regular system by the fact that trainees are transient groups. They attend training program to acquire specific skills and return to work to apply them. Over time, new knowledge and skill becomes necessary; again, they return to training program. Taking these analyses further, it is necessary to critically evaluate the following factors while designing and implementing online education methodology:

(a) Low Creativity \& Notional teaching. The students are more creative during the classroom sessions. Teachers also teach students based on student's absorption power or learning capacity. This is not feasible for a teacher in front of the camera. Teaching instruction is not teaching as instruction in the mind of students is not knowledge.

(b) Lack of Conducive Study Environment. They are committed to learning with discipline and ready to explore creativity. To explore creativity and discipline we need to provide an environment for students to learn. When taking online classes at home there are fewer chances to create an environment for study. It required support from other family members. That's not possible in joint families. This is a big disadvantage to study at home. Even getting the notification and mobile calls are also disturbed students to focus on study. Offline class in front of the teacher is highly focused on the topic and no one can disturb the classroom.

(c) No scope of Fun-Moments. The traditional teaching is healthy-mix of variety of human emotions. Sometimes class room environment is light, at times it is full of excitements or it may be hot or situations takes funny turn and everybody laughs. This varying environment breaks the monotony of the teaching. Teaching demands creativity also as any question may be shot by the student. But smile on faces of students gives confidence to teachers. All efforts are explored to ensure that students understand the topic. But onlinesessions have very limited scope of these fun moments of class rooms. Teachers are 
required to make them interesting at her own. This may limit the emotional attachment to subject from teachers. This may also be reason of stress for few teachers.

(d) Coordination Complications. Online teaching makes one to one communication more difficult. Therefore, coordinating various issues become difficult. A well-structured program limiting to available infrastructure and resources, in all likelihood will be successful.

(e) More Theoretical Teaching. Limited interaction makes these online sessions more theoretical. There is a chance that teachers may read the subject content from any website, book or prepared printed material.

(f) Ill-effect on Health. Online teaching is not beneficial for students from their health perspective specially eyes and ears. Prolonged online sessions may cause poor vision, strain injuries, and other physical health problems. Therefore, all participants are to be made aware about ill-effect on health. All to be advised for right sitting posture, desk height, etc.

All the teaching methodologies may not be fruitful for all kinds of students, nor are all students in the same situation to take-on online classes. So, before planning an online program, it is important that due consideration is given to - objectives, situation, available resources and their effectiveness, time, environment, capital investments etc. In essence it needs to be a balanced structure which will be productive for teachers and students.

\section{Recommendations}

Adequate attention to skill development reduces actual overhead financial burden of an organisation. Drawing from what Andy Molinsky (Molinsky, 2020) observes on virtual meetings, operating in new ways - and moving to online platforms will push many of us out of our comfort zones. It's important to acknowledge that while online-training is different, and challenging in some ways, it also has number of advantages. Various aspects required for productive onlinetraining, based on our own experience of conducting more than two hundred online sessions for Graduate and Post Graduate level management students, are elaborated below:

\section{Flip Classes \& Webinars as tools}


What one sees, retains longer; in comparison to what one reads and listens. Flip classes with covering the video of a place or activity is one of the finest ways to impart education. Conduct of Webinars on the relevant subject with appropriate Q\&A provides a platform for effective eLearning. Such interactions help students to streamline their approach and goals for the successful tomorrow.

One of the premier management institutions of Greater Noida, in Delhi NCR has nicely designed and practicing the oriented training programme. Wherein the Institute management successfully conducted number of International Virtual Summits, National Virtual summits and series of Webinars. Renowned professionals and Experts from various fields of Technical, Finance, Health, Management studies. Enthusiasm of guest speakers as well as the students made such events productive. Such online-interactions, demonstrations of documentaries and subject based Films etc maybe other means to enhance the vision and approach of the students and trainees.

\section{Recommended Online Training Methodology}

A reliable and feasible laid down Online-training methodology is essential for effective and efficient training in any organisation. The training teams may consider to formulate and implement an Online-Training programme based on specific objectives and considering existing resources. This needs to address all the relevant variables for smooth functioning of an organisation. As Rohan Singh and Madhumita Mohanty point out, it important to remember that effective training programs are systematic and continuous. In other words, training must be viewed as a long-term process, not just an infrequent and / or haphazard event (Singh \& Mohanty, 2012).

Drawing from the findings of 2019 Training Industry Report (Freifeld, 2019), it is necessary to be well acquainted with available online Learning Management System (LMS) and other applications before undertaking such task. The institutions must make LMS look professional and inviting. One needs to be conversant with capabilities as well as limitations of the LMS for better exploitation. Lack of any digital action will lower the trust of participant.

Exhaustive studies by scholars like Tannenbaum and Yukl (Tannenbaum \& Yukl, 1992) point to factoring the objectives, frequency, duration, resources and number of trainees for Online Training merits consideration before formulating the schedule. The typical Online Training methodology, therefore may be formulated as below: 
(a) Announce / publicise the 'Online Training-schedule' well in time.

(b) Date, Time, Venue, Subject, Name of trainer etc must be mentioned explicitly.

(c) Quiz / Tests / Objective type Examinations on the Subject.

(d) Record of Online Training conducted needs to be meticulously maintained. This will add to the evaluation of the philosophy of the organisation. This will help in improving the experience for everyone next time.

(e) It needs to include the following: -

(i) Lessons Learnt-Academic and Technical, both

(ii) Subjective content anomalies

(iii) Degree of success in developing a personal connection with online trainees. All time objective is to ensure the involvement of all the participants in a session.

(iv) Grey areas of trainees observed

(v) Out-of-Box ideas for any productive activity observed during interaction of class.

(vi) Individual progress on the subject in Quiz / Tests / MCQ based Examinations on the Subject.

(vii) Trainees' observations on conduct as well as content of the Online Training sessions. An electronic tool leaves electronic traces and same can be utilised in improving our efforts.

(viii) Specific point for trainers to be ensure in next sessions. Practically, one may prepare for next course while teaching.

(ix) Technical \& / or procedural difficulties encountered by trainees.

(x) Technical glitches observed

(xi) Likely modifications required in next sessions. 
(xii) Exploit the Chat / Q\&A function as we stay connected and engaged in the focussed training. This enables students to 'Raise Hand' or to comment in real time as I'm talking.

Most vital point for online sessions is the Connectivity with your participants. Degree of connectivity detects the degree of success of the sessions. There are many ways to achieve the higher degree of success. Few of them may be:-

(a) Prepare mentally for the task and make it your personal objective to be achieved.

(b) Be courteous with all the students. Convey Warmth and concern, you will be reciprocated.

(c) Ensure the sessions are not monotonous. Make it Interactive by light fun moments.

(d) Get used to delayed feedback.

\section{Conclusion}

Most of the educational institutions have resorted to distance learning teaching doe to contagious nature of COVOD-19 pandemic. Training is an interactive and systematically organised practice for enhancement of the knowledge of the students. Online-teaching is unusual methodology of teaching, thus needs technical resources with manageable tech skills. But initial grappling with the complexities of distance education will make the system more reliable in due course. Addressing teething connectivity challenges is the major subject of concern. Complexities are not only tech in nature. Non-technical issues are more frequent in regular course of teaching. These challenges are multidimensional. Designing and delivering content to students, supporting teachers to handle monotonous sessions, providing guidance to parents, etc., are few of them.

Mere conduct of an Online Training program is not end of the teaching process. Organizations need to regularly evaluate and review whether training $\&$ development programs are effective and producing the desired objectives. For prolific distance learning teaching, we must conduct the process in letter and spirit. A framework structured with amalgamation of skills and capabilities begins with a training-gap (training needs) analysis and a description of how to bridge or fill the gap. 


\section{References}

Aguinis, H., \& Kraiger, K. (2009). Benefits of Training and Development for Individuals and Teams, Organizations,and Society. Annual Review of Psychology, 60(1), 451-474. doi:10.1146/annurev.psych.60.110707.163505

Chimote, N. K. (2010). Training Programs: Evaluation of Trainees 'expectations and experience. The IUP Journal of Organizational Behavior, IX(3), 28-47.

Colombo, E., \& Luca, S. (2008, February). The Impact of Training on Productivity: Evidence from a Large Panel of Firms. International Journal of Manpower, 35(8), 1140-1158. doi:https://doi.org/10.1108/IJM-082012-0121

Ellis, A., Bell, B., Ployhart, R., Hollenbeck, J., \& Ilgen, D. (2005). An evaluation of generic teamwork skills training with action teams: Effects on cognitive and skill-based outcomes. Personnel Psychology, 58(3), 641-672. doi:https://doi.org/10.1111/j.1744-6570.2005.00617.x

Freifeld, L. (2019, November 06). 2019 Training Industry Report. Retrieved from https://trainingmag.com/: https://trainingmag.com/trgmag-article/2019-training-industry-report/

Gutierrez, K. (2016, April 07). Facts and Stats That Reveal The Power Of eLearning [Infographic]. Retrieved May 01, 2020, from https://www.shiftelearning.com/: https://www.shiftelearning.com/blog/bid/301248/15-facts-and-stats-that-reveal-the-power-of-elearning

Huque, A., \& Vyas, L. (2008). Expectations and performance: assessment of public service training in Hong Kong. The International Journal of Human Resource Management, 19(1), 188-204.

Li, C., \& Lalani, F. (2020, May 04). Students retain more in online classrooms, shows data. Retrieved May 07, 2020, from https://theprint.in/: https://theprint.in/india/education/students-retain-more-in-onlineclassrooms-shows-data/412669/

Marks, M., Sabella, M., Burke, C., \& Zaccaro, S. (2002). The impact of cross-training on team effectiveness. Journal of Applied Psychology, 87(1), 3-13. doi:10.1037/0021-9010.87.1.3

McDaniel, M. A., \& Schlager, M. S. (1990). Discovery Learning and Transfer of Problem-Solving Skills. Cognition and Instruction, 7(2), 129-159.doi:10.1207/s1532690xci0702_3

Molinsky, A. (2020, March 19). Virtual Meetings Don't Have to Be a Bore. Retrieved from www.hbr.org: https://hbr.org/2020/03/virtual-meetings-dont-have-to-be-a-bore

Panotop. (2019, July 24). Why Employee Training Fails And How To Prevent It In Your Organization. Retrieved from www.panotop.com/: https://www.panopto.com/blog/why-employee-training-fails/

PTI. (2020, April 27). Fixed line broadband users, data usage surge due to lockdown: Report. Retrieved from https://economictimes.indiatimes.com/: https://economictimes.indiatimes.com/tech/internet/fixedline-broadband-users-data-usage-surge-due-to-lockdown-report/articleshow/75405986.cms

PTI. (2020, April 27). Fixed line broadband users, data usage surge due to lockdown: Report. Retrieved from https://economictimes.indiatimes.com/: https://economictimes.indiatimes.com/tech/internet/fixedline-broadband-users-data-usage-surge-due-to-lockdown-

report/articleshow/75405986.cms?\%20utm_source=contentofinterest\&utm_medium=text\&utm_campaign $=$ cppst 
Rama Devi, V., \& Shaik, N. (2012). Evaluating training \& development effectiveness - A measurement model. Asian Journal of Management Research, 2(1), 722-735.

Singh, R., \& Mohanty, M. (2012). Impact of Training Practices on Employee Productivity: A Comparative Study. Interscience Management Review, 2(2), 87-92.

Tannenbaum, S., \& Yukl, G. (1992). Training and development in work organizations. Annual Review of Psychology, 43, 399-441. doi:https://doi.org/10.1146/annurev.ps.43.020192.002151

UNESCO. (2020, March 19). Half of world's student population not attending school: UNESCO launches global coalition to accelerate deployment of remote learning solutions. Retrieved from https://en.unesco.org/: https://en.unesco.org/news/half-worlds-student-population-not-attending-schoolunesco-launches-global-coalition-accelerate

UNESCO. (2020, May). The Need to Collect Essential Education Data During the COVID-19 Crisis. Retrieved from http://tcg.uis.unesco.org/: http://tcg.uis.unesco.org/wpcontent/uploads/sites/4/2020/07/Fact-sheet-58-Need-for-Education-Data-COVID19-Final.pdf

UNESCO. (2020, March 26). UNESCO rallies international organizations, civil society and private sector partners in a broad Coalition to ensure \#LearningNeverStops. Retrieved from https://en.unesco.org/: https://en.unesco.org/news/unesco-rallies-international-organizations-civil-society-and-private-sectorpartners-broad

UNESCO. (n.d.). Adverse consequences of school closures. Retrieved from https://en.unesco.org/: https://en.unesco.org/covid19/educationresponse/consequences

UNESCO. (n.d.). COVID-19 Impact on Education. Retrieved from https://en.unesco.org: https://en.unesco.org/covid19/educationresponse

Vemic, J. (2007). Employee Training and Development and the Learning Organization. Economics and Organization, 4(2), 209-216. Retrieved from http://facta.junis.ni.ac.rs/eao/eao200702/eao200702-13.pdf

Wentworth, D. (2016, November 30). Top Spending Trends for Training, 2016-2017. Retrieved from https://trainingmag.com/: https://trainingmag.com/top-spending-trends-training-2016-2017 